Hispania, 2021, vol. LXXXI, n. ${ }^{\circ}$ 269, septiembre-diciembre, págs. 743-766 ISSN: 0018-2141, e-ISSN: 1988-8368, https://doi.org/10.3989/hispania.2021.019

\title{
Tratamiento cinematográfico del Valle de los Caídos en NO-DO desde una perspectiva de análisis basada en su tratamiento simbólico*
}

\author{
Diego Naranjo Moraga ${ }^{1}$ \\ Universidad Rey Juan Carlos \\ diegonaranjomoraga@gmail.com
}

\section{Rebeca Suárez-Álvarez ${ }^{2}$}

Universidad Rey Juan Carlos

rebeca.suarez@urjc.es

RESUMEN: La presente investigación estudia la presencia del Valle de los Caídos en el noticiario cinematográfico NO-DO en el periodo de tiempo comprendido desde 1943, fecha de la primera proyección del noticiario, hasta 1981, última proyección y desaparición de la entidad. Se analiza la significación simbólica del Valle de los Caídos y pretende ser una contribución a las investigaciones desarrolladas en torno al discurso y la retórica del régimen dictatorial sobre la apropiación simbólica de lugares emblemáticos usados como espacios de la memoria histórica. Examina el tratamiento informativo del monumento aplicando la metodología de investigación multimodal en la que convergen técnicas cuantitativas y cualitativas que permiten conocer su valor, significado y evolución significativa. Su principal conclusión es que, si bien es cierto que el Valle de los Caídos se consolidó como la máxima expresión arquitectónica del franquismo, no obstante, NO-DO presenta un desfase alegórico, ideológico y estético que no coincide con la tendencia de expandir el poder con la propaganda o con la confianza en el protagonismo de las masas de los años 40 al inicio de su construcción.

* Siglas de archivos: Archivo General de la Administración, Alcalá de Henares, Madrid (AGA).

${ }^{1}$ ORCID iD: https://orcid.org/0000-0001-7678-9296

2 ORCID iD: https://orcid.org/0000-0002-0102-4472

Copyright: (C) 2021 CSIC. Este es un artículo de acceso abierto distribuido bajo los términos de una licencia de uso y distribución Creative Commons Reconocimiento 4.0 Internacional (CC-BY 4.0) 


\section{Palabras clave: NO-DO; Valle de los Caídos; tratamiento simbólico; cine; información.}

The cinematographic approach to the Valle de los Caídos in NO-DO newsreels, analysing their symbolic treatment

ABSTRACT: This research studies the presence of the Valle de los Caidos in NO-DO cinema newsreels from 1943, the date of the first news projection, until 1981, with the last projection and NODO's disappearance. The paper analyses the symbolic significance of the Valle de los Caidos and seeks to contribute to the research surrounding the discourse and rhetoric of Franco's dictatorship regarding the symbolic appropriation of emblematic places used as spaces of historical memory. It examines the way the monument was dealt with in the news, applying a multimodal research methodology in which quantitative and qualitative techniques converge to gauge the evolution of its value, meaning and significance. Our main conclusion is that, although the Valle de los Caidos became consolidated as the maximum architectural expression of Franco's regime, the NO-DO presented an allegorical, ideological and aesthetic mismatch which diverged both from the tendency to expand power by means of propaganda and from confidence in the active popular participation of the 1940s when construction began.

KEY WORDS: NO-DO; Valle de los Caídos; symbolic treatment; motion pictures; information.

CÓMO CITAR ESTE ARTÍCULO / CITATION: Naranjo, Diego y Suárez-Álvarez, Rebeca, «Tratamiento cinematográfico del Valle de los Caídos en NO-DO desde una perspectiva de análisis basada en su tratamiento simbólico», Hispania, 81/269 (Madrid, 2021): 743-766. https://doi.org/10.3989/hispania.2021.019.

\section{INTRODUCCIÓN}

A raíz de la decisión del gobierno de Pedro Sánchez (PSOE) de exhumar los restos del cadáver de Francisco Franco del Valle de los Caídos se generó un debate por el valor simbólico del monumento que continúa creando polémica después de más de cuarenta años de la muerte del dictador. Un debate que se trasladó a la opinión pública de las «dos Españas», de las que hablaba Machado, cada vez más polarizada: una que considera la transición como una nueva hoja en blanco y otra que considera necesaria la reparación, también simbólica, de la etapa franquista. Esta investigación tiene como objetivo el análisis de los lugares de la memoria franquista a través del estudio de las imágenes del noticiario que servía como herramienta del régimen para trasladar su ideología al pueblo a través del cine.

Se aborda la imagen del Valle de los Caídos desde un enfoque histórico, diferente al mediático actual, tanto por el medio utilizado de fuente primaria, como por la metodología y la perspectiva analítica empleada. Esta investigación 
pretende relacionar la influencia del noticiario cinematográfico oficial de la dictadura franquista sobre la construcción simbólica del conjunto monumental formulando dos hipótesis. La primera se centra en comprobar si el régimen franquista se ve obligado a adaptar la simbología y el discurso inicial del Valle de los Caídos a la evolución de las circunstancias históricas a través de NO-DO y la segunda hipótesis versa sobre si el Valle de los Caídos no obtuvo la repercusión mediática en NO-DO que podía presumirse de un monumento de tal magnitud entendido como la conceptualización del poder en la dictadura.

\section{El noticiario Cinematográfico NO-DO}

Gutiérrez y Sánchez Alarcón afirman que la historia no se define únicamente a través de los acontecimientos políticos o económicos, pese a la importancia que les son atribuidos tradicionalmente, la memoria también es parte esencial del entramado que constituye el devenir histórico. Esta memoria colectiva es, a su vez, producto de los significados generados en la acción comunitaria de los individuos que integran un grupo social en cada momento histórico. En este sentido, destaca la importancia de la función que ejercen los medios de comunicación masivos, que no solo median en el traslado del conocimiento de la realidad presente, sino que tienen un peso esencial en la reconfiguración del pasado $^{3}$. En especial, los autores señalan el cine documental como la producción donde la recuperación de la memoria del acontecimiento se torna más visible, ya que las fuentes orales se demuestran vivas como en ningún otro medio, aumentando por ello su capacidad inductora para el recuerdo ${ }^{4}$. Estos motivos, entre otros, justifican el interés y la necesidad de un régimen totalitario por monopolizar y controlar los medios, caso del régimen franquista a través de NO-DO analizado en este trabajo.

\subsection{EI NO-DO como organismo}

De NO-DO destaca su tardía creación en comparación con otros organismos relacionados con la prensa y la propaganda del régimen franquista. Uno de los motivos que justifica dicha tardanza se debe a la importante y compleja tarea legislativa que suponía la creación de un medio de difusión propio del Estado en condición de monopolio ${ }^{5}$. Pese a que durante la Guerra Civil ya empieza a considerarse de vital importancia la industria cinematográfica como

\footnotetext{
${ }^{3}$ HOSKINS, 2001.

${ }^{4}$ GUTIÉRREZ y SÁNCHEZ ALARCÓN, 2005.

5 RODRÍGUEZ TRANCHE y SÁNCHEZ-BIOSCA, 2000.
} 
herramienta de control y organización de la información ${ }^{6}$ y la propaganda con el fin de volver a la opinión pública en contra del enemigo, las primeras condiciones para la creación de un noticiario estatal se empiezan a dar en febrero de 1938.

El primer paso para construir un noticiario oficial se da el 14 de enero de 1937 con la creación de la Delegación del Estado para Prensa y Propaganda, en dependencia directa de la Secretaría General del Estado y con el falangista Vicente Gay a la cabeza, al que le sucedieron el comandante Manuel Arias Paz y, posteriormente, el comandante José Moreno Torres. Como registra el Boletín General del Estado (BOE), en la orden de 12 de enero de 1937, a esta nueva delegación se le confiere condición persuasiva de la propaganda siempre que sea para la «buena causa» $\rangle^{7}$ de la inculcación de ideología propia.

En febrero de 1938, con la creación del primer gobierno franquista, la delegación pasa a llamarse Delegación Nacional de Prensa y Propaganda y cede su dependencia al Ministerio del Interior, con Ramón Serrano Súñer como director. Esta delegación contará, por primera vez, con una división efectiva de competencias: Dirección General de Propaganda y Dirección General de Prensa. Dependiente de ambas divisiones se crea, en el mismo año, un Servicio de Radiodifusión y un Departamento Nacional de Cinematografía dirigido por Manuel Augusto García Viñolas. Este nuevo organigrama tenía como principal función la consolidación de la estructura central del «Nuevo Estado» y el rechazo de la autonomía de sectores políticos ${ }^{8}$. Esta es una prueba de la toma de conciencia sobre la importancia de la propaganda durante la que se definirá el control de la información, la censura, la acuñación de un lenguaje oficial léxico propio («rojos», «alzamiento», «cruzada») y argumentos orientados a deslegitimar la lucha de los contrarios.

El 1 de abril de 1938, durante la guerra civil, se crea el Departamento Nacional de Cinematografía (DNC) que, con solo dos meses de vida, pone en marcha el Noticiario Español y logra alcanzar 32 ediciones con un total de 164 noticias entre junio de 1938 y marzo de $1941^{9}$, números que, de no ser por la ayuda alemana, no hubieran sido posibles ${ }^{10}$. La repercusión del noticiario fue limitada, dada la reducida difusión y accidentada periodicidad durante la contienda. Sin embargo, sirvió como campo de pruebas del que más tarde saldría NO-DO. Su principal función durante la posguerra fue como medio de aleccionamiento de las poblaciones recién ocupadas, ejemplos son Madrid y Barcelona, donde,

${ }^{6}$ CAMARERO, 2002. SÁNCHEZ-BIOSCA, 2007.

7 BOE, 3 de mayo de 1937: 59, Agencia Estatal Boletín Oficial del Estado.

8 BIZCARRONDO, 1996.

9 RODRÍGUEZ TRANCHE, 2006: 115.

10 AGUINAGA, 2006. 
tras ser ocupadas por el ejército de Franco se empezaron a proyectar de manera gratuita en los principales cines ${ }^{11}$.

A pesar de esto, el noticiario entró en una fase de lenta agonía y apenas conseguirá superar la edición por mes al acabar la guerra ${ }^{12}$ debido a la falta de apoyo alemán en ese momento, la consecuente disminución del ritmo de producción y a que no recibe ningún tipo de favor frente a los noticiarios comerciales que compiten con él. En 1940, Viñolas, consciente del deterioro de $\mathrm{DNC}^{13}$ propone en un informe ${ }^{14}$ la creación de una Dirección General de Cinematografía inspirada en el modelo italiano, basada en una organización de propaganda cinematográfica del Estado y protegida por el mismo.

Se firma un nuevo convenio cinematográfico, el 26 de abril de 1940, por parte del presidente de la Reichfilmkammer ${ }^{15}$, García Viñolas y Santos Bollar, presidente de la Subcomisión Reguladora de la Cinematografía, cuyo fruto sería la creación de NO-DO. Tras la crisis política de mayo de 1941, propiciada por los sectores monárquicos del régimen y por la progresiva influencia de FET y las JONS ${ }^{16}$, junto con la intención de Súñer de dar un carácter más fascista al régimen, se pone fin total al DNC y, con él, al Noticiario Español.

Esta crisis de 1941 desencadenó una restructuración de los servicios de propaganda. Con esta, la Secretaría General del Movimiento, dirigida por el falangista José Luis de Arrese, pasó a tener rango de ministerio, trasladando al mismo las actividades relacionadas con prensa y propaganda de las que Súñer había sido destituido. Dependiente de esta secretaría se crea la Vicesecretaría de Educación Popular de FET y de las JONS, como organismo aglutinador de las actividades de prensa y propaganda. Esta vicesecretaría tendrá, a su vez, cuatro secciones denominadas Delegaciones Nacionales: Prensa, Propaganda, Radiodifusión y Cinematografía y Teatro. Al frente de la vicesecretaría se nombra a Gabriel Arias Salgado, que se encargaría de controlar la propaganda de forma ajena a la influencia falangista. Con esta nueva administración se pretende lograr un cambio en la propaganda audiovisual volcada ahora en producir mensajes de carácter institucional, con una apariencia menos exaltada que en la etapa anterior, de la que saldrá NO-DO. Hernández ${ }^{17}$ sostiene que el interés por la producción de este

11 DIEZ, 1997.

12 Trece ediciones realizadas en el periodo de tiempo que va de mayo de 1939 a marzo de 1940.

13 Esta decadencia de la propaganda política española por parte del DNC se puso de manifiesto al cubrir la entrevista entre Franco y Hitler en Hendaya el 23 de octubre de 1940.

${ }^{14}$ Informe de García Viñolas, Madrid, 31/VII/1940, AGA, Ministerio de Cultura, caja 153.

15 Corporación estatal de la Alemania nazi que reguló la industria cinematográfica con fines propagandísticos entre 1933 y 1945.

${ }^{16}$ La Falange Española Tradicionalista y de las Juntas de Ofensiva Nacional Sindicalista. Único partido permitido por el régimen franquista tras la Guerra Civil. Fundado y liderado por Franco en 1937 y disuelto en 1977.

17 HERNÁNDEZ, 2008. 
tipo de series documentales proyectadas en TVE durante el franquismo, bajo la concepción franquista de televisión pública como empresa cultural y educativa al servicio del régimen, se debe a su finalidad como herramienta destinada a reforzar y exaltar la identidad nacional del público español.

El 25 de agosto de 1941, Arias Salgado dispone, mediante una orden interior, la transformación de DNC en Sección de Cinematografía. Sin embargo, estos cambios no logran frenar la lenta agonía de los servicios oficiales de cinematografía por falta de medios y huida del personal por motivos económicos, tal y como afirmaba Argamasilla ${ }^{18}$, jefe del Negociado de Producción de la sección. Por estos motivos, se nombra un nuevo jefe de producción y se crean dos nuevos equipos de producción, con el objetivo de producir, al menos, un documental de 300 metros $^{19}$, así como cubrir eventos puntuales que pudieran surgir. Junto con estas peticiones, Argamasilla propone, por primera vez el 24 de abril de 1942, realizar un noticiario oficial con la idea de establecer un monopolio en la producción y la exhibición del noticiario ${ }^{20}$. Para ello, vuelve a reclamar recursos y señala el contrasentido de la existencia de tres noticiarios.

El 28 de mayo de 1942, el jefe del Servicio Nacional de Prensa y Propaganda de la Delegación Nacional de Sindicatos, José Manuel Quiroga, escribe una carta dirigida a Carlos Fernández Cuenca, jefe del Departamento de Cinematografía de la Delegación Nacional de Propaganda, solicitándole autorización para organizar un «noticiario español cinematográfico». Así, en un informe, el presidente de la Subcomisión Reguladora de Cinematografía, Joaquín Soriano, quien, meses después, sería director de NO-DO, aseguraba que la Sección de Cinematografía debía asumir «la edición de un noticiario nacional y la producción de buenos documentales de propaganda $\rangle^{21}$. NO-DO, además, sirve para cerrar la rivalidad entre distintos sectores y estamentos oficiales que pugnaban por producir un noticiario estatal. Un noticiario oficial abría una nueva fase en la propaganda franquista. Así lo justificaba el preámbulo del Reglamento de NO-DO22:

\footnotetext{
Desde la final de nuestra gloriosa Cruzada de Liberación ha venido convirtiéndose en una necesidad [...] la edición del noticiario cinematográfico nacional información española y extranjera que, con carácter exclusivo, sirva a los fines de propaganda de la política del nuevo Estado.
}

\footnotetext{
18 ARGAMASILLA, 1940.

19 Medida de longitud de una lata de cinta, el equivalente a 10-12 minutos de film (duración media de los noticiarios).

${ }^{20}$ RODRÍGUEZ TRANCHE y SÁNCHEZ-BIOSCA, 2000.

${ }^{21}$ Memoria sobre la situación de los organismos oficiales de cinematografía, escrita por Joaquín Soriano, Madrid, 16/VI/1942, página 13, AGA, Ministerio de Cultura, caja 45.

${ }_{22}$ Reglamento para la organización y funcionamiento de la entidad productora, editora y distribuidora cinematográfica de carácter oficial «NO-DO», Madrid, 29/9/1942, página 5, AGA, Ministerio de Cultura, caja 113.
} 
Con el objetivo de que el régimen se expresara con una sola voz, se dota al noticiario de exclusividad, siguiendo el modelo de Alemania e Italia. Todo ello se materializa en la creación de NO-DO en septiembre de 1942. El noticiario UFA $^{23}$ cubría casualmente los llamados sucesos de Begoña ${ }^{24}$ y consiguió imágenes del atentado. Entonces, el vicesecretario de Educación Popular llamó a su director para que se pusiera en contacto con el noticiario Fox y le cediese una copia de las imágenes, pero este se resistió, tratándolo de exclusiva periodística, pese a que las autoridades así lo exigieron. Este suceso hizo pensar en la conveniencia de contar con un noticiario único oficial.

El 29 de septiembre la Vicesecretaría de Educación Popular de FET y de las JONS establece el acuerdo de creación de NO-DO. Torres López, delegado nacional de propaganda, se encargó de redactar su reglamento ${ }^{25}$, en el que se especifican las competencias administrativas, las funciones, con la edición de un noticiario y la producción de documentales, el régimen económico, la vinculación orgánica con la vicesecretaría y las atribuciones del director. El reglamento también recogía una primera interpretación de su régimen jurídico que le otorgaba personalidad económica, jurídica y administrativa propia.

Joaquín Soriano, presidente de la Subcomisión Reguladora de la Cinematografía, dejaría el cargo el 6 de octubre de 1942, para convertirse en el primer director de NO-DO. Resuelto lo anterior, quedaba el problema de la escasa disposición de medios para llevarlo a la práctica ${ }^{26}$. La solución radicó en la búsqueda de recursos ajenos, así, se pidió ayuda a las casas editoras de noticiarios en España para que aportaran medios o efectivos para la creación de NO-DO. Algunos ejemplos son el de la casa Fox en nuestro país que proporciona su personal, incluso a su director, Días Amado, al que se le otorga el cargo compensatorio de asesor de la Sección de Documentales, o la aportación decisiva de la filial española de UFA, que poseía los mejores medios y efectivos para realización de noticiarios. Paradójicamente, estas

${ }^{23}$ Universum Film AG, el estudio cinematográfico más grande e importante de Alemania en ese momento. A finales de octubre, el delegado de UFA, Friedrich von Kondratonvicz, viene a España para discutir el asunto con la vicesecretaría. Un mes más tarde, se firma un acuerdo a cambio de que NO-DO cediera la explotación de las noticias y reportajes de interés que realizara sobre España, en exclusiva, a los alemanes; y también de que NO-DO hablase de Alemania como del país que gozaba de una situación favorable en el conflicto, monopolizando así las noticias que en España se difundían sobre la guerra.

${ }^{24}$ Atentado fallido al general Varela, ministro del Ejército, monárquico y contrario a Serrano Súñer. Tuvo lugar el 16 de agosto de 1942 en la bilbaína basílica de Nuestra Señora de Begoña, durante una ceremonia organizada por los tradicionalistas a la que asistía el ministro del Ejército, y en la que unos jóvenes falangistas lanzaron dos granadas ocasionando setenta heridos leves.

${ }_{25}$ Reglamento para la organización y funcionamiento de la entidad productora, editora y distribuidora cinematográfica de carácter oficial «NO-DO», Madrid, 29/9/1942, AGA, Ministerio de Cultura, caja 113.

${ }^{26}$ Memoria sobre la situación de los organismos oficiales de cinematografía, escrita por Joaquín Soriano, Madrid, 16/VI/1942, AGA, Ministerio de Cultura, caja 45. 
ayudas debían lograrse a la vez que se prohibía la actividad de sus noticiarios en España. Además, se hace imprescindible el aporte alemán, que en ese momento mantenía estrechas relaciones con el régimen, que simpatizaba con su causa de la guerra y sostenía una posición de no beligerancia ante el conflicto.

Reig, subdirector de NO-DO desde su inauguración, se postulaba como el candidato perfecto para dirigir NO-DO por su trayectoria en el sector, pero su germanofilia le invalidó para el cargo en beneficio de Soriano ${ }^{27}$. Una vez firmado el acuerdo el 14 de diciembre, Joaquín Soriano eleva al vicesecretario la propuesta de plantilla de NO-DO, procedente en su mayoría del noticiario UFA, la casa Fox y del mismo Servicio de Cinematografía y Subcomisión Reguladora de la Cinematografía. Este equipo dio constancia de su profesionalidad con la edición número 1 lista apenas quince días después. El 15 de diciembre, el asesor jurídico de la vicesecretaría emite un informe donde declara obligatoria su proyección y no ve objeción legal en ello. Dos días después, Arias Salgado, delegado Nacional de Propaganda, firma una nota en la que se comunica la aprobación y rubrica la Disposición de la Vicesecretaría de Educación Popular por la que se crea «la entidad de carácter oficial Noticiarios y Documentales Cinematográfi$\cos \mathrm{NO}-\mathrm{DO} »{ }^{28}$, que implicaba la supresión de todos los noticiarios anteriores y la prohibición a cualquier operador de realizar reportajes cinematográficos sin autorización de NO-DO o sin la firma de su director, Soriano. Además, constaba el propósito de ejercer un monopolio en el intercambio y la selección de noticias con noticiarios extranjeros ${ }^{29}$. Medidas propias de un régimen autoritario qué, antes de ejercer una política activa de propaganda, pretendía establecer un control sobre el sector. Poco después, el delegado Nacional de Propaganda envío una circular a los exhibidores con los objetivos del noticiario explicando que:

\begin{abstract}
NO-DO ha sido creado con el fin de producir y explotar el noticiario español, hacer llegar las noticias españolas al mundo entero, realizar documentales de propaganda general de nuestra patria, sirviendo al propio tiempo a los fines de prácticas y especialización de cuántos elementos nacionales lo merezcan, y construir un archivo general de cinematografía ${ }^{30}$.
\end{abstract}

El 30 de diciembre de 1942 ya está lista la edición número 1 del noticiario cinematográfico español NO-DO y se presenta ante la Comisión Nacional de Censura Cinematográfica sin que exista objeción alguna, según consta en el expediente de censura número 03866 del Archivo General del Ministerio de Cultura. Por último,

27 RODRÍGUEZ TRANCHE y SÁNCHEZ-BIOSCA, 2000.

${ }_{28}$ BOE, 22 de diciembre de 1942, número 365, Agencia Estatal Boletín Oficial del Estado.

29 Reglamento para la organización y funcionamiento de la entidad productora, editora y distribuidora cinematográfica de carácter oficial «NO-DO», Madrid, 29/9/1942, AGA, Ministerio de Cultura, caja 113.

${ }^{30}$ CABERO, 1949: 518. 
cumpliendo lo dispuesto, el lunes 4 de enero de 1943 el noticiario se estrena oficialmente en las pantallas, día que empieza la actividad pública y oficial de NO-DO. Esta primera edición tiene una longitud especial, 680 metros, de la que se produjeron 100 copias distribuidas por la empresa Alianza Cinematográfica Española ${ }^{31}$ (ACE), la misma que hasta ese momento había distribuido el noticiario UFA.

El principal método de obtención de ingresos de NO-DO se establecería posteriormente en una disposición del Ministerio de Industria y Comercio, de 23 de febrero de 1943, con carácter retroactivo. Estos ingresos dependerían de unas tarifas de precios variables, que NO-DO establecería en cada sala, en función de sus ingresos brutos, por el alquiler del noticiario a los exhibidores. La tarifa no podía sobrepasar el 3,5\% de los ingresos brutos de la sala ${ }^{32}$. El porcentaje causó continuas protestas y manifestaciones de los exhibidores, que lo consideraban excesivo, ocasionando subidas y bajadas del mismo. Su otra fuente secundaria de ingresos fue el dinero recibido de los Presupuestos Generales del Estado ${ }^{33}$.

La última etapa de la entidad comienza con una orden, emitida el 22 de agosto de 1975 por parte del Ministerio de Información y Turismo, que eliminaba la obligatoriedad de exhibición del noticiario. Quedaba expuesto al desinterés de los exhibidores y su resistencia a pagar tales cantidades por su alquiler. En esta situación, la Dirección General de Cinematografía, con Félix Benítez de Lugo al frente, realiza, en junio de 1977, un detallado estudio sobre la situación del organismo. En este, además de exponer su involución, proponía redefinir los cometidos de NO-DO: ampliar sus funciones al servicio de la educación popular, la propaganda en el exterior, la creación de un archivo histórico y asumir el papel de la extinta Escuela Oficial de Cinematografía. Se había producido un aumento desproporcionado de la plantilla y un descenso de ingresos por las exhibiciones del noticiario que hacían peligrar la situación financiera de la entidad ${ }^{34}$. No obstante, la producción de NO-DO se mantendría hasta el 25 de mayo de 1981, cuando aparece la última edición, número $1.966 \mathrm{~B}$.

Algunos autores, como Juristo ${ }^{35}$, confirman que la presencia de NO-DO provocó el descontento de las productoras privadas de películas documentales que, pese a que el organismo aseguraba en su normativa que no pretendía ser competencia por no poseer fines lucrativos, sí marcaba, como aseguraba Soriano,

${ }^{31}$ Se constituye en Barcelona en 1933 con la intención de distribuir en España la producción de UFA. Forman la sociedad Manuel Carreras Macaya, Juan Cortada Jané, Pedro de Vallescar Pallí y Ramón de Vallescar Pallí.

${ }^{32}$ BOE, 30 de marzo de 1944, Agencia Estatal Boletín Oficial del Estado.

${ }^{33}$ Reglamento para la organización y funcionamiento de la entidad productora, editora y distribuidora cinematográfica de carácter oficial «NO-DO», Madrid, 29/9/1942, página 5, AGA, Ministerio de Cultura, caja 113.

${ }^{34}$ Situación de NO-DO. Informe de la Dirección General de Cinematografía, Madrid, 1977, página 3, AGA, Ministerio de Cultura, caja 80046.

35 JURISTO, 2008. 
«un camino que podía ser seguido por todas las productoras nacionales» ${ }^{36}$. Estas limitaciones a la libertad de creación, unido a la preferencia de los exhibidores por la proyección del noticiario, debido a su obligatoriedad, en lugar de producciones españolas de complemento, condicionaron un retraso de una industria documental en España.

\subsection{EI NO-DO como archivo histórico}

Una vez extinguido el organismo, quedaba pendiente la custodia, conservación y uso de sus fondos. Una opción era confiar su salvaguarda a la Filmoteca Nacional, que no solo atesoraba la producción del organismo, sino que también poseía otros materiales relacionados, como por ejemplo el Archivo Real ${ }^{37}$. La alternativa era incorporarlo en el archivo de RTVE. Esta cuestión ocasionó un gran debate por parte de los dos organismos, que fue trasladado a medios de comunicación y a la política ${ }^{38}$.

Ante este debate, el diputado de Coalición Democrática, Antonio de Senillosa, manifiesta en el congreso, el 21 de febrero de 1980, su preocupación por que los fondos de NO-DO dependieran de RTVE y el posible uso indebido que podría hacer de los mismos. Argumentaba que «se trata de un legado cultural que es patrimonio del pueblo español y necesario para la investigación, por lo que debe conservarse íntegramente ¿para qué, si no, existe la Dirección General de Cinematografía cuyos fines son precisamente estos? ${ }^{39}$. Tras estas palabras, el ministro de Cultura, Ricardo de la Cierva, informó de la creación de una comisión mixta, entre RTVE y la Dirección General de Cinematografía, para estudiar el destino definitivo de los fondos lo antes posible. El 20 de mayo de 1980, el Ministerio de Cultura dispuso la integración de los fondos cinematográficos NO-DO en la Filmoteca Nacional por coincidir con sus funciones. Aunque perjudicaba a RTVE, la orden contemplaba, ante posibles objeciones, que «podría obtener, con cargo a sus presupuestos, una copia de cuantas producciones cinematográficas considerara necesarias para sus funciones» ${ }^{40}$.

La última regulación al respecto, actualmente vigente, aparece en la Ley 1/1982 de 24 de febrero que crea el organismo autónomo Filmoteca Española, en sustitución de la anterior Filmoteca Nacional. Con este cambio se

36 SORIANO, 1943.

${ }^{37}$ Fondos localizados en el Palacio Real de Madrid, constituidos por piezas documentales sobre distintas actividades de la familia real y, especialmente, del reinado de Alfonso XIII, que NO-DO duplicó en soportes de seguridad.

38 RODRÍGUEZ TRANCHE y SÁNCHEZ-BIOSCA, 2000.

39 Diario de sesiones del Congreso de los diputados, Cortes Españolas, Sesión Plenaria 66, 21 de febrero, 1980: 4420.

${ }^{40}$ BOE, 11 de julio de 1980, Agencia Estatal Boletín Oficial del Estado. 
autorizaba a RTVE el uso con carácter gratuito del material cinematográfico para la producción de sus propios programas de televisión y radio. En este mismo año, el noticiario toma el nombre de Archivo Histórico NO-DO. De esta manera, NO-DO (instalaciones, equipos y personal) se integra en RTVE, pero su patrimonio audiovisual queda bajo la competencia de Filmoteca Española. Para evitar el deterioro de los materiales por la demanda de copias de materiales y consultas, en 1989 se procedió a copiar en soporte de video todas las ediciones del noticiario producidos entre 1943 y 1981, un total de 4.016 entre otros archivos.

\section{LA CONSTRUCCIÓN SIMBÓliCA DEL VALLE DE LOS CAÍdOS}

El régimen franquista, como la mayoría de las dictaduras, dio una gran importancia a la concepción del espacio como componente ritual de sus actos, buscando un estilo arquitectónico propio que sirviera para representar su ideario. De esta manera, se empiezan a tomar tempranas medidas legislativas, a instancias de Eugenio d'Ors, director de la Jefatura Nacional de Bellas Artes, y se crea la Comisión de Estilo en las Conmemoraciones de la Patria ${ }^{41}$, en febrero de 1938. Dicha comisión, en combinación con el Departamento de Plástica, daría origen, en el mismo año, al Departamento de Ceremonial y Plástica, dependiente de la Delegación Nacional de Prensa y Propaganda, cuya función fue la construcción de monumentos y la organización de conmemoraciones, desfiles y actos patrióticos que buscaban la legitimidad del régimen con símbolos y decorados del pasado más querido. Asimismo, pretendía establecer unas normas estéticas con unos mismos fines propagandísticos: exaltación de la figura del caudillo, obras conmemorativas de la victoria y de homenaje a los «caídos».

Se produce un intento normativo para crear el llamado estilo franquista, con la ley de 23 de septiembre de $1939^{42}$, que crea la Dirección General de Arquitectura, a cuyo frente se sitúa a Pedro Muguruza Otaño, posteriormente encargado del proyecto del Valle de los Caídos. Con él, cobran especial relevancia, por su número, los monumentos dedicados a conmemorar las gestas de la guerra civil.

El día 1 de abril de 1940, coincidiendo con el primer «Aniversario de la Victoria» de la Guerra Civil, Franco firma un decreto para institucionalizar la construcción del Valle de los Caídos, como «lugar de meditación y de

${ }^{41}$ La Comisión de Estilo en la Conmemoraciones de la Patria, el mismo año, daría origen, en combinación con el Departamento de Plástica, al Departamento de Ceremonial y Plástica, dependiente de la Delegación Nacional de Prensa y Propaganda.

${ }^{42}$ BOE, 2 de abril de 1940, Agencia Estatal Boletín Oficial del Estado. 
reposo en que las generaciones futuras rinden tributo de admiración a los que les legaron una España mejor» ${ }^{43}$. El comienzo de las obras se costeó con el sobrante de un fondo de 234 millones y medio de pesetas ${ }^{44}$ que Franco consiguió durante la guerra gracias a donaciones de particulares. Ante futuras problemáticas de financiación, se decide organizar una lotería el 5 de mayo de cada año, cuyos beneficios se destinarán íntegramente al sufragio de las obras del conjunto monumental. Tras 19 años de construcción y una inversión total de $1.086 .460 .331,89$ pesetas $^{45}$, se celebra la inauguración y apertura pública del Valle de los Caídos el día 1 de abril de 1959.

La significación de este tipo de monumentos ligados a un capital simbólico no fija relatos ni sentidos invariables, sino que poseen un carácter cronológicamente mutante ${ }^{46}$. Se hace imprescindible afrontar este tipo de patrimonio desde una perspectiva cambiante y no como un elemento del pasado rígido en el tiempo. Así lo ratifica Iniesta ${ }^{47}$, argumentando que «ya no es "la cosa", sino el discurso socialmente construido al que "la cosa" sirve de soporte», la forma en la que este tipo de monumentos «impregna los sucesivos presentes». En esta línea, Simón ${ }^{48}$ señala que una de las constantes históricas para dar legitimidad a los regímenes políticos es la construcción de lugares de memoria que transmitan valores, ideologías y lecturas del pasado. Fernández ${ }^{49}$ y Cuesta Bustillo han trabajado en el desarrollo historiográfico de estas realidades. Bustillo ${ }^{50}$ aborda la construcción de la memoria historia como objetivo histórico, concluyendo que resulta de textura frágil y que es construida a través de la legitimidad que se les otorga a los vencedores. Afirma que la «batalla por las memorias $\rangle^{51}$, que se celebra anualmente en el aniversario del régimen o de algún monumento histórico originario del mismo, se fundamenta en el sustrato ideológico del partido vencedor que, junto con el pasado imperial, logra instituirse como un discurso legitimador.

Las situaciones cambiantes por la que ha pasado el Valle de los Caídos, fruto de la continua presencia de nuevos sujetos interpretativos y la redefinición de marcos y escenarios desde el inicio de su construcción en 1940 hasta el presente, hacen que, como recoge Ferrándiz ${ }^{52}$, haya experimentado

${ }^{43}$ BOE, 2 de abril de 1940, Agencia Estatal Boletín Oficial del Estado.

44 Diario $A B C$, «Especial Valle de los Caídos (I)», 1959, en Coleccionable 70 años de $A B C$, núm. 50.

45 SUEIRO, 1976.

${ }^{46}$ NORA, 1989.

47 INIESTA e INIESTA, 2009: 478.

48 SIMÓN, 2019.

49 FERNÁNDEZ, 1995.

${ }^{50}$ BUSTILLO, 1998.

${ }^{51}$ BUSTILLO, 2007.

52 FERRÁNDIZ, 2011: 485. 
las siguientes fases anacrónicas: anacronismo nostálgico con sectores sociales afines al legado político y simbólico del régimen, que releen el monumento de forma neofranquista; anacronismo indiferente, que se entiende como un tema que no molesta, sin interés ni transcendencia; anacronismo incómodo, centrado en sectores que no quieren identificarse con la significación originaria y no encuentran un anclaje para su relectura; y anacronismo hiriente de sectores que lo consideran apología del fascismo y ofensa a los vencidos. Entendiendo las fases, se puede inferir que el origen de las controversias asociadas a la gestión actual del patrimonio franquista, como es el caso del Valle de los Caídos, y los ciclos conmemorativos asociados a ellas, viene determinado por las reacciones anacrónicas de ciertos sectores de la sociedad española contemporánea. Este descontento se ha materializado en las exhumaciones contemporáneas, como uno de los últimos episodios de los ciclos históricos de desenterramientos y reacomodo de cadáveres ${ }^{53}$, desde que acabó la guerra civil y desde que los muertos del bando vencedor han sido localizados, desenterrados y vueltos a enterrar con el fin de incorporarlos a ciclos conmemorativos y proyectos monumentales. De esta forma, el franquismo elabora una construcción histórica de los héroes y mártires «caídos por Dios y por España», con la ayuda de monumentos de carácter redentor y sacrificial sobre el conflicto ${ }^{54}$. Por ello, en el Valle de los Caídos se ha llevado a cabo, desde 1959 hasta el último registro, de 3 de julio de 1983, una gran importación de cadáveres de tumbas y fosas comunes de todo el país, que tenía como fin ser casa común de héroes y mártires de la guerra.

Olmedo ${ }^{55}$ sostiene la hipótesis de que el cambio del discurso oficial sobre el traslado de restos de ambos bandos no se correspondía con el deseo del régimen de una transformación simbólica del Valle de los Caídos, ya que solo admitían a «rojos católicos descarriados que se dejaron seducir por las mentiras de la anti-España ${ }^{56}$. A pesar de las declaraciones públicas que trataban de encubrirlo como un espacio de reconciliación y perdón cristiano, sostiene que se estaba construyendo un monumento franquista, proveniente del pensamiento nacional-católico, con la simbología del movimiento y que se planteaba incluir fallecidos del otro bando con el único fin de evitar las protestas de las familias del bando republicano. El mismo autor justifica la presencia de los restos republicanos como la utilización política del miedo, o forma pedagógica de

53 Algunos, como el fundador de la Falange, Primo de Rivera, ha sido enterrado tres veces. Actualmente yace en el valle.

54 FERRÁNDIZ, 2011.

55 OLMEDO, 2009.

${ }^{56}$ En el año 1958, el ministro de la Gobernación, Camilo Alonso Vega, llama a cobijar en el Valle muertos «sin distinción del campo en el que combatieran, según impone el espíritu cristiano de perdón que inspiró su creación, siempre que, unos y otros, fueran de nacionalidad española y de religión católica» (ALONSO, 1958). 
sangre, que ayudaba a sustentar el régimen, y como etiquetador cotidiano de la presencia de diferentes tipos de muertos en la guerra: los héroes, los caídos y los mártires, acuñados por la retórica oficial, reforzada por la construcción de monumentos y la realización de conmemoraciones.

Según Ferrándiz ${ }^{57}$, el Valle de los Caídos puede definirse como un monumento anacrónico que comenzó a desviarse desde su inauguración, que culminaba y cerraba una época. El uso de presos políticos en las obras es una de las representaciones del saqueo constante de los recursos de los vencidos y el dominio de los vencedores. El carácter marcadamente religioso del monumento, unido al militarismo, define la alianza profunda y estable del franquismo con la Iglesia y el Ejército, componentes básicos del nacionalcatolicismo.

En definitiva, el Valle de los Caídos ha sido usado como espacio de la memoria histórica, concepto entendido por Rodrigo ${ }^{58}$ como «reivindicación política, social, cultural y moral, tanto del republicanismo español de antes y durante la guerra civil, como de la resistencia antifranquista durante la dictadura, así como los valores supuestamente colectivos y compartidos por las y los vencidos». Sobre esta definición, Moreno ${ }^{59}$ concluye que estas operaciones aseverativas o reivindicativas requieren de la capacidad de los medios para construir contenidos donde se insertan discursos e interpretaciones explicativas que se hacen eco de valores colectivos, pero que también se trasladarán a la cultura social: es lo que el autor denomina «memoria mediática», que interrelacionará este monumento con la memoria colectiva a través de NO-DO.

\section{Metodología}

Se emplea la triangulación metodológica, recurriendo a la combinación de análisis cuantitativos y cualitativos. Se observa un universo de 4.016 noticia$\operatorname{rios}^{60} \mathrm{NO}-\mathrm{DO}$, sumando el número total de las ediciones de las tres series, según recopilan Tranche y Biosca ${ }^{61}$ : 1.922 ediciones de la serie A, 1.764 ediciones de la serie B y 330 ediciones de la serie C. Las series surgen como solución a los problemas de distribución de los noticiarios, que podían llegar a repetirse en el mismo cine durante más de un mes. Se decidió hacer 3 ediciones

57 FERRÁNDIZ, 2011.

58 RODRIGO, 2006: 12.

59 MORENO, 2016.

${ }^{60}$ Es necesario distinguir noticiarios de documentales. Pese a pertenecer al mismo organismo, se trataba de producciones diferentes por su carácter informativo. Este trabajo solo tratará las producciones NO-DO referentes al noticiario.

${ }^{61}$ RODRÍGUEZ TRANCHE y SÁNCHEZ-BIOSCA, 2000: 163. 
diferentes de un mismo NO-DO, con pequeñas variaciones, para rotar entre cines cercanos y no dejar caer el interés del espectador.

De este universo de noticiarios, al introducir el descriptor «Valle de los Caídos» en el buscador del Archivo Histórico de NO-DO de la Filmoteca Española, se encuentran indexados un total de 46 unidades de muestreo o noticiarios $\mathrm{NO}-\mathrm{DO}$ en los que se hace alusión explícita al monumento. A partir de esta segmentación, se procede a un análisis documental utilizando un protocolo de análisis de fuente propia con el objetivo de describir y representar los documentos fílmicos de forma sistemática y unificada para facilitar su recuperación, permitiendo captar e interrelacionar ideas esenciales.

En este protocolo de análisis se diseñó un formulario con las siguientes variables de categorización: número de NO-DO, fecha, duración total, total de bloques, duración de la parte relativa al valle, nombre de la sección o noticia a la que pertenece, porcentaje de la duración de la parte que corresponde al valle respecto al total del noticiario, posición del bloque del valle dentro del total, transcripción de la narración de la parte e imágenes relevantes de la parte. A partir de ello, se realiza el análisis descriptivo y cualitativo del contenido de los noticiarios como elementos discursivos creadores de significación, retóricas y argumentos legitimadores, a través de círculos temáticos y contenidos destacados de las partes dedicadas al Valle de los Caídos en NO-DO.

\section{Resultados}

Se analizan las referencias al conjunto monumental a través de las imágenes, texto, narración, duración, estructura y cronología de los noticiarios NO-DO presentados en las pantallas cinematográficas e indexados en la Filmoteca Española con la referencia «Valle de los Caídos». El análisis cuantitativo de los noticiarios documentales NO-DO, desde su primera proyección el 4 de enero de 1943 hasta la última, el 25 de mayo de 1981, en las que se hace referencia directa a «Valle de los Caídos» muestra el limitado interés del noticiario por el conjunto monumental. En concreto, de la totalidad de 1.408 números de NO-DO y sus distintas ediciones A, B y C, que conforman un total de 4.016 noticiarios producidos entre 1943 y $1981^{62}$, se han localizado 46 noticiarios que hacen referencia explícita al Valle de los Caídos, es decir, 1,15 \% del total de los mismos.

${ }^{62}$ RODRÍGUEZ TRANCHE y SÁNCHEZ-BIOSCA, 2000: 608. Se detecta un error en la columna correspondiente al total anual del año 1944, que en vez de ser 30 son 90. 
Tabla 1. Noticiarios con Referencias al Valle de los Caídos entre 1943 y 1981

\begin{tabular}{|c|c|c|c|c|c|}
\hline NÚMERO & FECHA & NÚMERO & FECHA & NÚMERO & FECHA \\
\hline $256 \mathrm{~B}$ & $01 / 12 / 1947$ & $890 \mathrm{~B}$ & $25 / 01 / 1960$ & $1143 \mathrm{~B}$ & $20 / 11 / 1964$ \\
\hline $354 \mathrm{~B}$ & $17 / 10 / 1949$ & $894 \mathrm{~B}$ & $22 / 02 / 1960$ & $1195 \mathrm{~B}$ & $29 / 11 / 1965$ \\
\hline $412 \mathrm{~B}$ & $27 / 11 / 1950$ & $910 \mathrm{~A}$ & $03 / 06 / 1960$ & $1220 \mathrm{~A}$ & $23 / 05 / 1966$ \\
\hline $458 \mathrm{~B}$ & $15 / 10 / 1951$ & $915 \mathrm{~A}$ & $18 / 07 / 1960$ & $1225 \mathrm{~A}$ & $27 / 06 / 1966$ \\
\hline 593 B & $17 / 05 / 1954$ & $932 \mathrm{~A}$ & $14 / 11 / 1960$ & $1260 \mathrm{~B}$ & $27 / 02 / 1967$ \\
\hline 598 A & $21 / 06 / 1954$ & $939 \mathrm{~B}$ & $02 / 01 / 1961$ & $1299 \mathrm{~B}$ & $27 / 11 / 1967$ \\
\hline $786 \mathrm{~B}$ & $27 / 01 / 1958$ & $985 \mathrm{C}$ & $20 / 11 / 1961$ & $1326 \mathrm{~B}$ & $03 / 06 / 1968$ \\
\hline $812 \mathrm{~B}$ & $28 / 07 / 1958$ & $986 \mathrm{~A}$ & $27 / 11 / 1961$ & $1456 \mathrm{~B}$ & $30 / 11 / 1970$ \\
\hline $848 \mathrm{~B}$ & $06 / 04 / 1959$ & $1018 \mathrm{~A}$ & $09 / 07 / 1962$ & $1508 \mathrm{~B}$ & $29 / 11 / 1971$ \\
\hline $848 \mathrm{~A}$ & $06 / 04 / 1959$ & $1038 \mathrm{~B}$ & $26 / 11 / 1962$ & $1560 \mathrm{~A}$ & $27 / 11 / 1972$ \\
\hline $851 \mathrm{~A}$ & $27 / 04 / 1959$ & $1040 \mathrm{~B}$ & $10 / 12 / 1962$ & $1574 \mathrm{~B}$ & $05 / 03 / 1973$ \\
\hline $874 \mathrm{~B}$ & $05 / 10 / 1959$ & $1041 \mathrm{~A}$ & $17 / 12 / 1962$ & $1605 \mathrm{~B}$ & $08 / 10 / 1973$ \\
\hline $875 \mathrm{~B}$ & $12 / 10 / 1959$ & $1065 \mathrm{~B}$ & $03 / 06 / 1963$ & $1697 \mathrm{~B}$ & $21 / 07 / 1975$ \\
\hline $877 \mathrm{~A}$ & $26 / 10 / 1959$ & $1087 \mathrm{C}$ & $04 / 11 / 1963$ & $1766 \mathrm{~B}$ & $29 / 11 / 1976$ \\
\hline $882 \mathrm{~B}$ & $30 / 11 / 1959$ & $1109 \mathrm{~B}$ & $06 / 04 / 1964$ & & \\
\hline $888 \mathrm{~A}$ & $11 / 01 / 1960$ & $1125 \mathrm{~B}$ & $27 / 07 / 1964$ & TOTAL & 46 \\
\hline
\end{tabular}

Fuente: elaboración propia.

TABla 2. Distribución CRONOlÓGICA DE los nOticiarios CON REFERENCIA AL VAlle de LOS CAÍdOS ENTRE 1943 y 1981

\begin{tabular}{|c|c|c|c|c|c|c|c|}
\hline Año & $\begin{array}{c}\text { Noticiarios } \\
\text { con } \\
\text { referencias }\end{array}$ & $\begin{array}{c}\text { Noticiarios } \\
\text { totales }\end{array}$ & $\mathbf{\%}$ & Año & $\begin{array}{c}\text { Noticiarios } \\
\text { con } \\
\text { referencias }\end{array}$ & $\begin{array}{c}\text { Noticiarios } \\
\text { totales }\end{array}$ & $\%$ \\
\hline 1943 & 0 & 85 & $0,00 \%$ & 1963 & 2 & 156 & $1,28 \%$ \\
\hline 1944 & 0 & 90 & $0,00 \%$ & 1964 & 3 & 156 & $1,92 \%$ \\
\hline 1945 & 0 & 75 & $0,00 \%$ & 1965 & 1 & 156 & $0,64 \%$ \\
\hline 1946 & 0 & 59 & $0,00 \%$ & 1966 & 2 & 156 & $1,28 \%$ \\
\hline 1947 & 1 & 104 & $0,96 \%$ & 1967 & 2 & 108 & $1,85 \%$ \\
\hline 1948 & 0 & 104 & $0,00 \%$ & 1968 & 1 & 106 & $0,94 \%$ \\
\hline 1949 & 1 & 104 & $0,96 \%$ & 1969 & 0 & 104 & $0,00 \%$ \\
\hline 1950 & 1 & 104 & $0,96 \%$ & 1970 & 1 & 104 & $0,96 \%$ \\
\hline 1951 & 1 & 104 & $0,96 \%$ & 1971 & 1 & 104 & $0,96 \%$ \\
\hline 1952 & 0 & 106 & $0,00 \%$ & 1972 & 1 & 104 & $0,96 \%$ \\
\hline 1953 & 0 & 104 & $0,00 \%$ & 1973 & 2 & 104 & $1,92 \%$ \\
\hline 1954 & 2 & 104 & $1,92 \%$ & 1974 & 0 & 104 & $0,00 \%$ \\
\hline 1955 & 0 & 104 & $0,00 \%$ & 1975 & 1 & 100 & $1,00 \%$ \\
\hline 1956 & 0 & 104 & $0,00 \%$ & 1976 & 1 & 104 & $0,96 \%$ \\
\hline 1957 & 0 & 106 & $0,00 \%$ & 1977 & 0 & 79 & $0,00 \%$ \\
\hline 1958 & 2 & 104 & $1,92 \%$ & 1978 & 0 & 52 & $0,00 \%$ \\
\hline 1959 & 7 & 104 & $6,73 \%$ & 1979 & 0 & 48 & $0,00 \%$ \\
\hline 1960 & 6 & 117 & $5,13 \%$ & 1980 & 0 & 52 & $0,00 \%$ \\
\hline 1961 & 3 & 156 & $1,92 \%$ & 1981 & 0 & 22 & $0,00 \%$ \\
\hline 1962 & 4 & 159 & $2,52 \%$ & TOTAL & 46 & 4016 & $1,15 \%$ \\
\hline
\end{tabular}

Fuente: elaboración propia. 
Tabla 3. Duración y orden de las noticias sobre el Valle de los Caídos (DICIEMBRE 1947-NOVIEMBRE 1976)

\begin{tabular}{|c|c|c|c|c|c|c|}
\hline NÚMERO & FECHA & $\begin{array}{l}\text { DUR. } \\
\text { PARTE }\end{array}$ & $\begin{array}{c}\text { DUR. } \\
\text { TOTAL }\end{array}$ & PORCENTAJE & SECCIÓN & POSICIÓN \\
\hline $256 \mathrm{~B}$ & $01 / 12 / 1947$ & $01: 18$ & $10: 10$ & $12,79 \%$ & 5 & 5 \\
\hline $354 \mathrm{~B}$ & $17 / 10 / 1949$ & $00: 56$ & 10:09 & $9,20 \%$ & 5 & 1 \\
\hline $412 \mathrm{~B}$ & $27 / 11 / 1950$ & $01: 11$ & $10: 04$ & $11,75 \%$ & 9 & 9 \\
\hline $458 \mathrm{~B}$ & $15 / 10 / 1951$ & 00:18 & $10: 10$ & $2,95 \%$ & 8 & 8 \\
\hline $593 \mathrm{~B}$ & $17 / 05 / 1954$ & $00: 46$ & $10: 02$ & $7,64 \%$ & 6 & 1 \\
\hline $598 \mathrm{~A}$ & $21 / 06 / 1954$ & $01: 22$ & $10: 33$ & $12,95 \%$ & 5 & 1 \\
\hline $786 \mathrm{~B}$ & $27 / 01 / 1958$ & $00: 18$ & $10: 24$ & $2,88 \%$ & 10 & 1 \\
\hline $812 \mathrm{~B}$ & $28 / 07 / 1958$ & $00: 46$ & $10: 13$ & $7,50 \%$ & 8 & 5 \\
\hline $848 \mathrm{~B}$ & $06 / 04 / 1959$ & $02: 59$ & $10: 04$ & $29,64 \%$ & 5 & 5 \\
\hline $848 \mathrm{~A}$ & $06 / 04 / 1959$ & $02: 50$ & $10: 14$ & $27,69 \%$ & 6 & 1 \\
\hline $851 \mathrm{~A}$ & $27 / 04 / 1959$ & $00: 31$ & $10: 10$ & $5,08 \%$ & 7 & 1 \\
\hline $874 \mathrm{~B}$ & $05 / 10 / 1959$ & $00: 34$ & $10: 17$ & $5,51 \%$ & 7 & 1 \\
\hline $875 \mathrm{~B}$ & $12 / 10 / 1959$ & $00: 17$ & $10: 22$ & $2,73 \%$ & 10 & 2 \\
\hline $877 \mathrm{~A}$ & $26 / 10 / 1959$ & $00: 28$ & 10:08 & $4,61 \%$ & 7 & 2 \\
\hline $882 \mathrm{~B}$ & $30 / 11 / 1959$ & 01:06 & $10: 23$ & $10,59 \%$ & 7 & 1 \\
\hline $888 \mathrm{~A}$ & $11 / 01 / 1960$ & $00: 55$ & $10: 06$ & $9,08 \%$ & 7 & 2 \\
\hline $890 \mathrm{~B}$ & $25 / 01 / 1960$ & $00: 36$ & $10: 36$ & $5,66 \%$ & 10 & 3 \\
\hline $894 \mathrm{~B}$ & $22 / 02 / 1960$ & $00: 32$ & $10: 30$ & $5,08 \%$ & 10 & 1 \\
\hline $910 \mathrm{~A}$ & $03 / 06 / 1960$ & $01: 18$ & $09: 59$ & $13,02 \%$ & 6 & 6 \\
\hline $915 \mathrm{~A}$ & $18 / 07 / 1960$ & $00: 30$ & $10: 15$ & $4,88 \%$ & 6 & 3 \\
\hline $932 \mathrm{~A}$ & 14/11/1960 & 00:43 & 09:47 & $7,33 \%$ & 13 & 5 \\
\hline $939 \mathrm{~B}$ & $02 / 01 / 1961$ & $00: 58$ & $09: 38$ & $10,03 \%$ & 5 & 5 \\
\hline $985 \mathrm{C}$ & $20 / 11 / 1961$ & $00: 51$ & $09: 32$ & $8,92 \%$ & 4 & 1 \\
\hline $986 \mathrm{~A}$ & $27 / 11 / 1961$ & $00: 48$ & $09: 33$ & $8,38 \%$ & 5 & 1 \\
\hline $1018 \mathrm{~A}$ & $09 / 07 / 1962$ & $00: 54$ & $09: 52$ & $9,12 \%$ & 3 & 3 \\
\hline $1038 \mathrm{~B}$ & $26 / 11 / 1962$ & $00: 52$ & 09:38 & $9,00 \%$ & 4 & 1 \\
\hline $1040 \mathrm{~B}$ & $10 / 12 / 1962$ & $00: 38$ & 09:48 & $6,46 \%$ & 4 & 1 \\
\hline $1041 \mathrm{~A}$ & $17 / 12 / 1962$ & 01:02 & $09: 28$ & $10,92 \%$ & 4 & 3 \\
\hline $1065 \mathrm{~B}$ & $03 / 06 / 1963$ & $00: 21$ & 09:30 & $3,68 \%$ & 9 & 3 \\
\hline $1087 \mathrm{C}$ & $04 / 11 / 1963$ & $00: 22$ & 09:36 & $3,82 \%$ & 4 & 1 \\
\hline $1109 \mathrm{~B}$ & $06 / 04 / 1964$ & $01: 49$ & $09: 45$ & $18,63 \%$ & 7 & 1 \\
\hline $1125 \mathrm{~B}$ & $27 / 07 / 1964$ & $00: 22$ & $09: 57$ & $3,69 \%$ & 9 & 7 \\
\hline 1143 B & $20 / 11 / 1964$ & $00: 37$ & 09:34 & $6,45 \%$ & 3 & 1 \\
\hline $1195 \mathrm{~B}$ & $29 / 11 / 1965$ & $01: 25$ & 09:14 & $15,34 \%$ & 3 & 1 \\
\hline $1220 \mathrm{~A}$ & $23 / 05 / 1966$ & $00: 38$ & $10: 06$ & $6,27 \%$ & 3 & 1 \\
\hline $1225 \mathrm{~A}$ & $27 / 06 / 1966$ & $00: 29$ & $09: 50$ & $4,92 \%$ & 3 & 1 \\
\hline $1260 \mathrm{~B}$ & $27 / 02 / 1967$ & $00: 21$ & $10: 19$ & $3,39 \%$ & 3 & 1 \\
\hline $1299 \mathrm{~B}$ & $27 / 11 / 1967$ & $01: 17$ & $10: 17$ & $12,48 \%$ & 2 & 1 \\
\hline $1326 \mathrm{~B}$ & $03 / 06 / 1968$ & $00: 28$ & $10: 36$ & $4,40 \%$ & 3 & 1 \\
\hline $1456 \mathrm{~B}$ & $30 / 11 / 1970$ & 01:51 & $11: 08$ & $16,62 \%$ & 5 & 1 \\
\hline $1508 \mathrm{~B}$ & 29/11/1971 & 01:32 & $10: 51$ & $14,13 \%$ & 3 & 1 \\
\hline $1560 \mathrm{~A}$ & $27 / 11 / 1972$ & $01: 19$ & $10: 30$ & $12,54 \%$ & 3 & 1 \\
\hline $1574 \mathrm{~B}$ & $05 / 03 / 1973$ & $00: 28$ & $12: 18$ & $3,79 \%$ & 4 & 1 \\
\hline $1605 \mathrm{~B}$ & $08 / 10 / 1973$ & 01:07 & $10: 59$ & $10,17 \%$ & 4 & 1 \\
\hline $1697 \mathrm{~B}$ & $21 / 07 / 1975$ & $01: 29$ & $11: 06$ & $13,36 \%$ & 4 & 1 \\
\hline $1766 \mathrm{~B}$ & $29 / 11 / 1976$ & $01: 35$ & $10: 43$ & $14,77 \%$ & 4 & 1 \\
\hline
\end{tabular}

Fuente: elaboración propia. 
Figura 1. Evolución CRONOLÓGica del tiempo dedicado al Valle de los Caídos en el NOTICIARIO NO-DO

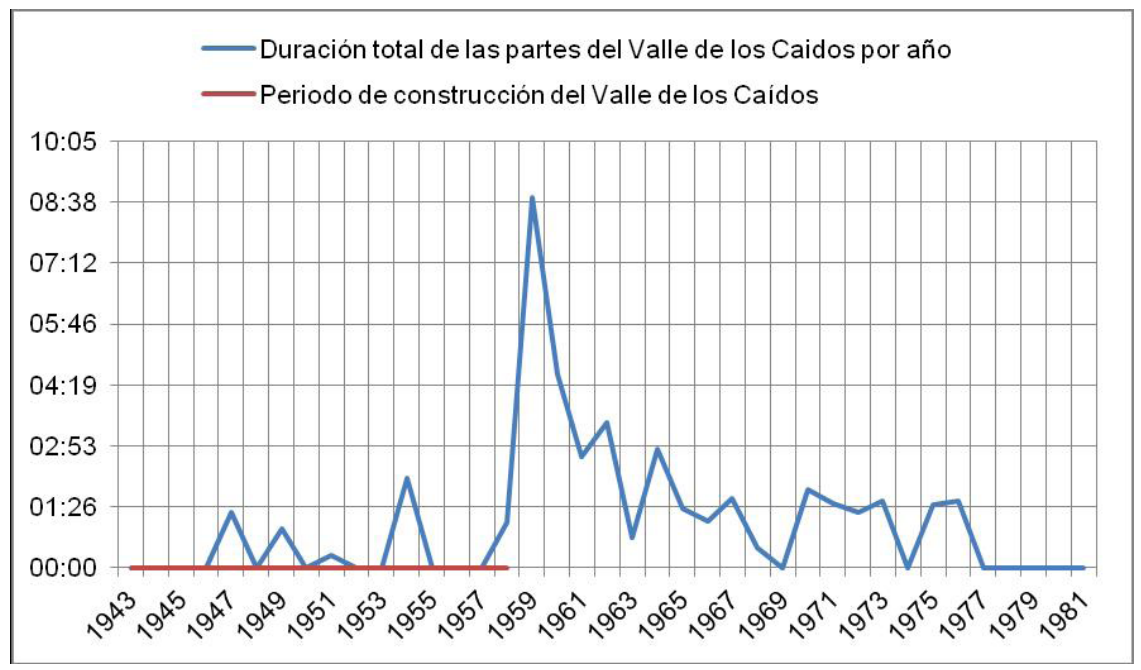

El análisis cronológico muestra que las informaciones contenidas en los noticiarios de NO-DO relativas al monumento no son solo a partir del 6 de abril de 1959, fecha de su inauguración y apertura al público, sino desde el inicio de su construcción. Antes de los noticiarios 848 A y 848 B, los cuales corresponden a su inauguración, encontramos 8 noticiarios con referencia explícita al Valle de los Caídos que van desde 1947 a 1958 y que constituyen el 17,4 \% del total de los 46 noticiarios.

El tiempo fílmico total centrado en el Valle de los Caídos fue de 43 minutos y 47 segundos de las 7 horas, 48 minutos y 24 segundos totales de los noticiarios en los que se hace referencia al mismo, es decir, una media de 9,35 minutos por cada 100 minutos de noticiario. El orden de aparición de las informaciones sobre el monumento también se considera un dato relevante. Las noticias sobre el Valle de los Caídos ocuparon en 29 ocasiones la sección en primera posición, frente a la última posición que solo ostentó en 5 ocasiones. Según teóricos como Tranche y Biosca ${ }^{63}$, en un noticiario que carece de una estructura definida que oriente y cree hábitos al espectador, la ubicación juega un papel especialmente importante, como elemento jerarquizador de la relevancia de las noticias: de esta manera aseguran que «prevalece la opción de colocar las noticias "duras" al comienzo» ${ }^{64}$. A partir del noticiario 1109 B (06/04/1964), que recoge el XXV Aniversario de la Paz celebrado en la basílica de la Santa

${ }^{63}$ RODRÍGUEZ TRANCHE y SÁNCHEZ-BIOSCA, 2000.

${ }^{64}$ RODRÍGUEZ TRANCHE y SÁNCHEZ-BIOSCA, 2000: 107. 
$\mathrm{Cruz}^{65}$, el Valle de los Caídos ocupará 14 primeras posiciones consecutivas en los NO-DO en los que se le hace referencia.

Tranche y Biosca ${ }^{66}$ también postulan la duración asignada a cada noticia como criterio para indicar relevancia al espectador. En este sentido, la duración media total, según los datos recabados, de las noticias dedicadas al Valle de los Caídos es de 57 segundos, lo que, frente a los estudios estadísticos de Del Amo García ${ }^{67}$ que aseguraban que la noticia-tipo, presente en la mayoría de ediciones, oscila entre los 50 y los 120 segundos de duración, podría considerarse normal. En 21 de los NO-DO analizados la referencia al Valle de los Caídos se sitúa en este rango de duración de la noticia-tipo, en 23 no superará los 50 segundos, por tratarse de referencias en las que el Valle de los Caídos es complemento a otra noticia, y solamente en 2 sobrepasará los 120 segundos. Estos dos noticiarios, 848 A y 848 B (06/04/1959), corresponden a la inauguración del monumento.

NO-DO, al ser un tipo de cine documental, ficcionaliza la realidad y construye una imagen desde un punto de vista determinado ${ }^{68}$, en este caso, el del régimen franquista. Condiciona a la opinión pública, entendida como interpretación preponderante de la mayoría de la población, con las imágenes y guiones de Alfredo Marqueríe; a través de la exclusividad y la obligatoriedad de la proyección del noticiario en las salas de cine; mediante la elección subjetiva de contenidos que obviaba informaciones que no beneficiaban a la dictadura, como las 14 muertes oficiales durante su construcción, el traslado de cadáveres con o sin consentimiento de las familias, o los retrasos que sufrió la construcción. Pese a ser un noticiario sometido al control estatal, los directivos de NO-DO ${ }^{69}$ afirman no haber recibido nunca consignas directas del régimen sobre su contenido. Si aseguran la existencia de una autocensura de los guionistas, que parecían conocer los límites de los noticiarios según las orientaciones deseadas por las autoridades, y lo alineaban con el discurso estatal. El NO-DO justificó la construcción del Valle de los Caídos aportando razones como «honrar a los que dieron su vida por España en el curso de la guerra de liberación», o agradecer a Dios su divina protección en las dificultades de la cruzada. Así lo expresa el noticiario 848 B (06/04/1959).

Se utilizó una fórmula común para las apariciones del monumento en NO-DO. En primer lugar, siempre se muestra la Cruz del Valle, que se convertirá en un elemento icónico para abrir y cerrar las partes relativas al mismo.

${ }^{65}$ Segundo acontecimiento con mayor porcentaje de duración dedicado al monumento del total de noticias analizadas.

${ }^{66}$ RODRÍGUEZ TRANCHE y SÁNCHEZ-BIOSCA, 2000.

${ }^{67}$ DEL AMO GARCÍA, 1993.

${ }^{68}$ ZUNZUNEGUI, 1984.

${ }^{69}$ SÁEZ, 2014. 
Le siguen unos planos de la explanada correspondiente a la basílica, donde el visitante o protagonista contempla la gran cruz. Posteriormente, dentro de la basílica, en la mayoría de las ocasiones, aparecen tres elementos principales: el Cristo crucificado o Cristo de las Batallas, las pinturas de la cúpula y la tumba de José Antonio Primo de Rivera.

Tras haber visionado y completado el formulario correspondiente al protocolo de análisis de elaboración propia propuesto en la metodología ${ }^{70}$, se lleva a cabo el tratamiento del análisis cualitativo de los contenidos informativos relativos al Valle de los Caídos. Mediante este, se logran distinguir varios círculos temáticos que orientan las noticias sobre el monumento y se procede a una clasificación temática en visitas turísticas (18 de 46), conmemoraciones de Primo de Rivera (11 de 46), inauguración (2 de 46) y otros eventos (14 de 46).

\section{Conclusiones}

Según la investigación realizada, puede concluirse que la hipótesis referida a que el régimen franquista se ve obligado a adaptar la simbología y el discurso inicial del Valle de los Caídos a la evolución de las circunstancias históricas a través de NO-DO se confirma. El Valle de los Caídos se consolidó como la máxima expresión arquitectónica del franquismo, concebido por Franco durante la guerra civil, y destinado a honrar la memoria de los mártires de la cruzada y dar gracias a Dios por la victoria. Sin embargo, NO-DO recoge un desfase alegórico, ideológico y estético que no coincide con la tendencia de expandir el poder con la propaganda o con la confianza en el protagonismo de las masas de los años 40, al inicio de su construcción. El Valle de los Caídos padece del mismo desfase temporal que el discurso inaugural que Franco pronunció en 1959. Encontrará como solución a su problema de adaptación la ritualización falangista de los $20 \mathrm{~N}$ y la peregrinación de invitados diplomáticos que lo dotan de una función más turística que doctrinal, como ya sucedía con el Alcázar de Toledo y El Escorial.

La edificación del Valle de los Caídos en 1940 coincide con el modelo arquitectónico nazi y con los ideales fascistas que emergían junto con la dictadura. Pero la inauguración del monumento veinte años más tarde, en 1959, estaba ya obsoleta y desfasada. La sociedad había evolucionado mucho a lo largo de estos

70 Dicho protocolo recopila las siguientes variables de cada parte de los NO-DO en las que se hace referencia al Valle de los Caídos: número de NO-DO, fecha, duración total, total de bloques, duración de la parte del Valle, nombre de la sección o noticia a la que pertenece, porcentaje de la duración de la parte que corresponde al Valle respecto del total del noticiario, posición del bloque del Valle dentro del total, transcripción de la narración de la parte, imágenes relevantes de la parte. 
años y había experimentado cambios estéticos, sociales, políticos e ideológicos que limitaron sobremanera el éxito esperado de la inauguración. De esta manera lo explica el teniente general Franco Salgado Araujo en 1957:

En España no hay ambiente para ese monumento, pues, aunque dure el miedo a otra guerra civil, gran parte de la población tiende a perdonar y olvidar [...]. Que si solo es para los blancos establecerá para siempre una eterna desunión entre los españoles ${ }^{71}$.

Las dimensiones para las que se concibió tampoco fueron las prácticas. Como mausoleo no logró concentrar a las masas más allá del día de su inauguración porque ya no eran movilizadas por el franquismo ni por el ideario fascista propio de la década de los 40 . Como centro de estudios e investigación fue escasamente nombrado por el noticiario. Como monasterio de la Orden Benedictina tuvo cierto éxito, con múltiples celebraciones religiosas, pero igualmente alejado de la exhibición pública. Como cripta cosechó su mayor éxito por el fulgor inicial del enterramiento de los restos de Primo de Rivera en 1959 y las conmemoraciones anuales del 20 de noviembre. En 1975, la inhumación de Franco provocaría un repunte mediático que dura hasta nuestros días.

También destaca un giro en la retórica del discurso franquista, propiciado por el paso del tiempo, hacia valores de paz e integración del vencido, que alcanzaría su clímax en 1964 con el discurso de XXV Aniversario de la Paz (1109 B), pero que el franquismo no desarrolló más adelante. Lo más significativo del nuevo discurso es que se dirige a las nuevas generaciones de españoles que no vivieron el trauma de la guerra civil, pero a las que se quiere inculcar el recuerdo de la evolución del triunfo en el que se da cabida a los contrincantes por el hecho de ser españoles y cristianos ${ }^{72}$.

La solución que el régimen pone sobre el conflicto anacrónico del discurso y de la significación del monumento en los noticiarios será engrosar su carácter religioso, menos erosivo en el tiempo, para atenuar el componente fascista, y la ritualización de actos políticos dedicados al duelo más que a las aclaraciones. Como consecuencia, aparte de las visitas turísticas, desde 1964 hasta el primer aniversario de la muerte de Franco en 1976, solo las conmemoraciones del 20N sacarán al monumento del anonimato en el noticiario NO-DO.

El destino del Valle de los Caídos como atracción turística ya se iba perfilando desde su inauguración, con numerosas noticias de visitas que se incrementarían con el paso del tiempo, dejando el discurso político y la simbología inicial del monumento al margen. Prueba de ello es el noticiario $1260 \mathrm{~B}$ (27/02/1967) en el que se puede ver al canciller Adenauer, primer canciller de la República Federal de Alemania y uno de los responsables de la desnazificación

${ }^{71}$ SALGADO-ARAUJO, 1976: 215.

72 ALONSO, 1958. 
de su país, visitando la obra más representativa del fascismo en España, el Valle de los Caídos. De forma sentenciosa, la edición 1697 B (21/07/1975) menciona la inauguración de un funicular en las inmediaciones del monumento, del que se dice que «aumenta el atractivo turístico del lugar».

Los resultados también confirman la segunda hipótesis referida a que el Valle de los Caídos no obtuvo la repercusión mediática en el NO-DO que podría presumirse de un monumento de tal magnitud, entendido como conceptualización del poder de la dictadura. Durante los años de emisión de NO-DO, el Valle de los Caídos ocupó 43:47 minutos de las 670 horas aproximadas que componen el total de las emisiones del noticiario. El año 1959 fue el año en el que más repercusión mediática logró con 8:45 minutos de emisión que coincide con la inauguración del monumento y la inhumación de Primo de Rivera. No se hacen referencias al Valle de los Caídos en 17 años de los 38 totales de la proyección del noticiario.

En este sentido, el análisis cualitativo de esta investigación, basado en la clasificación temática de las apariciones del conjunto monumental en el noticiario, concluye que la escasa celebridad que el Valle de los Caídos llega a conquistar durante la vida de NO-DO se debe, principalmente, a los dos motivos temáticos que justificaban la mayoría de sus apariciones. El primero, corresponde a su identificación como mausoleo de Primo de Rivera desde su inauguración, ligándolo a la Falange y a las conmemoraciones del 20N, ceremonias y eventos que el noticiario solía recoger anualmente. El segundo, se debe a su uso como uno de los lugares del paquete turístico ofrecido a embajadores, presidentes e ilustres que visitaban España, cuyo paso por el monumento era recogido por las cámaras, prueba de su evolución y reconversión a mera atracción turística en el mismo sentido que el Alcázar de Toledo y el monasterio de San Lorenzo del Escorial, abandonando toda connotación simbólica pasada, como prueba la visita del canciller Adenauer ${ }^{73}$.

\section{Bibliografía}

Aguilar Fernández, Paloma, Memoria histórica de la Guerra Civil Española (19361939): un proceso de aprendizaje político, tesis doctoral, Universidad Nacional de Educación a Distancia, 1995.

Aliaga Cárceles, José Javier, «Daniel Vázquez Díaz en las producciones de NO-DO: la difusión de los valores identitarios de su obra durante el franquismo», ASRI: Arte y sociedad. Revista de investigación, 16/9 (Murcia, 2019): 127-144.

Alonso Vega, Camilo, Circular de Camilo Alonso Vega del 31 de octubre, Madrid, Ministerio de Gobernación, 1958.

${ }^{73}$ Responsable de la desnazificación de Alemania, NO-DO, Noticiario 1260 B (27/02/1967). 
Amestoy, Alfredo, «La cara y la cruz del Valle de los Caídos», Altar Mayor, 112 (Madrid, 2007): 563-569.

Argamasilla de la Cerda y Elío, Joaquín María, «Informe de 26 de noviembre de 1941 de Joaquín Argamasilla», en Rafael Rodríguez Tranche y Vicente SánchezBiosca, NO-DO: el tiempo y la memoria, Madrid, Cátedra Filmoteca Española, 2000: 121-122.

Bizcarrondo Albea, Marta, «Cuando España era un desfile: el Noticiario Español», Catálogo General del Cine de la Guerra Civil, Madrid, Cátedra / Filmoteca Española, 1996: 73-90.

Cabero Martinez, Juan Antonio, Historia de la Cinematografía Española 1896-1849, Madrid, Gráficas Cinema, 1949.

Camarero Gómez, Gloria, La mirada que habla: cine e ideologías, Madrid, Akal, 2002.

Cuesta Bustillo, Josefina (ed.), Memoria e historia. Revista Ayer, $n .^{\circ}$ 32, Madrid, Marcial Pons, 1998.

Cuesta Bustillo, Josefina, «Las capas de la memoria. Contemporaneidad, sucesión y transmisión generacionales en España (1931-2006)», Hispania Nova, 7 (Madrid, 2007): 335-366.

Cuesta Bustillo, Josefina, La odisea de la memoria. Historia de la memoria en España, Madrid, Siglo XX / Alianza, 2008.

Del Amo García, Alfonso, «El noticiario NO-DO en el archivo. Archivos de la filmoteca», Revista de estudios históricos sobre la imagen, 15 (Valencia, 1993): 11-19.

Díaz Arias, Rafael, Periodismo en televisión: entre el espectáculo y el testimonio de la realidad, Barcelona, Bosch, 2006.

Diez Puertas, Emeterio, «La ocupación cinematográfica de Barcelona y Madrid», Secuencias: Revista de historia del cine, 6 (Madrid, 1997): 23-38.

Ferrándiz Martín, Francisco, «Guerras sin fin: Guía para descifrar el Valle de los Caídos en la España contemporánea», Política y sociedad, 48/3 (Madrid, 2011): 481-500.

Franco Salgado-Araujo, Francisco, Franco Bahamonde, Francisco y Padilla Bolívar, Antonio, Mis conversaciones privadas con Franco, Barcelona, Planeta, 1976.

González Sáez, Juan Manuel, «Ifni en el NO-DO (1943-1969)», Revista internacional de Historia de la Comunicación, 2 (Sevilla, 2014): 62-85.

Gutiérrez Lozano, Juan Francisco y Sánchez Alarcón, Inmaculada, «La memoria colectiva y el pasado reciente en el cine y la televisión: experiencias en torno a la constitución de una nueva memoria audiovisual sobre la Guerra Civil», $\mathrm{HMiC}$ : història moderna i contemporània, (Barcelona, 2005), https://raco.cat/index.php/ $\mathrm{HMiC} / \mathrm{article} / \mathrm{view} / 22066$.

Hernández Corchete, Sira, La historia contada en televisión. El documental televisivo de divulgación histórica en España, Barcelona, Gedisa, 2008.

Hoskins, Andrew, «New Memory: mediating history», Historical Journal of Film, Radio and Television, 21/4 (Leeds, Reino Unido, 2001): 333-346.

Iniesta, Alberto e Iniesta, González, Montserrat, «Patrimonio, ágora, ciudadanía: Lugares para negociar memorias productivas», en Ricard Vinyes (ed.), El Estado y la memoria: Gobiernos y ciudadanos frente a los traumas de la historia, Barcelona, RBA, 2009: 467-498. 
León Aguinaga, Pablo, «El comercio cinematográfico como instrumento de la acción norteamericana en España durante la segunda guerra mundial», Cuadernos de Historia Contemporánea, 28 (Madrid, 2006): 303-322.

Matud Juristo, Álvaro, «La incorporación del cine documental al proyecto de NO-DO», Historia y comunicación social, 13 (Madrid, 2008): 105-118.

Méndez González, Diego, «El Valle de los Caídos», Informes de la Construcción, 12/116 (Madrid, 1959): 37-62.

Moreno Garrido, Belén, Medios, imágenes y memoria: el Valle de los Caídos, tesis doctoral, Universidad Complutense de Madrid, 2016.

Nora, Pierre, «Between Memory and History: Les Lieux de Mémoire», Representations, 26 (Suiza, 1989): 7-25.

Olmeda Nicolás, Fernando, El Valle de los Caídos: Una memoria de España, Barcelona, Península, 2009.

Preston, Paul, Franco, Caudillo de España, Barcelona, DeBolsillo, 2004.

Rina Simón, César, «La memoria franquista en el espacio urbano: cuestiones metodológicas e historiográficas para las comisiones locales de memoria histórica», PH: Boletín del Instituto Andaluz del Patrimonio Histórico, 27/96 (Sevilla, 2019): 193-196.

Rodrigo, Javier, «La Guerra Civil, “memoria", "olvido", “recuperación” e instrumentación», Hispania Nova, 6 (Madrid, 2006): 12.

Rodríguez Tranche, Rafael, «La propaganda cinematográfica del bando nacional en la Guerra Civil española», en La Guerra Civil española 1936-1939: congreso internacional, Madrid 27, 28 y 29 noviembre de 2006, Madrid, Sociedad Estatal de Conmemoraciones Culturales (SECC), 2006.

Rodríguez Tranche, Rafael y Sánchez-Biosca, Vicente, NO-DO: el tiempo y la memoria, Madrid, Cátedra Filmoteca Española, 2000.

Sánchez-Biosca, Vicente, «Propaganda y mitografía en el cine de la guerra civil española (1936-1939)», CIC. Cuadernos de Información y Comunicación, 12 (Madrid, 2007): 75-94.

Soriano, Joaquín, «Orientación de NO-DO sobre documentales», Primer Plano, 123 (Madrid, 1943), 7-III-1943.

Sueiro, Daniel, La verdadera historia del Valle de los Caídos, Madrid, SEDMAY S. A., 1976, disponible en http://www.maalla.es/Libros/La\%20verdadera\%20 historia $\% 20$ del $\% 20$ Valle\%20de $\% 2010$ \% $\% 20$ Caidos.pdf

Zunzunegui Díez, Santos, Mirar la imagen, San Sebastián, Universidad del País Vasco, 1984.

Recibido: $24 / 02 / 2020$

Aceptado: 20/11/2020 